\title{
From Which Point Do We Begin? On Combining the Multiliteral and Multiperspectival
}

\author{
Bradley, Joff P. N. · Cabell, Charles \\ (Teikyo University · Toyo University) \\ Cole, David R. · Kennedy, David H. · Poje, Joseph* \\ (Western Sydney University · Nihon University · Teikyo University)
}

Bradley, Joff P. N.; Cabell, Charles; Cole, David R.; Kennedy, David H.; Poje, Joseph. (2018). From which point do we begin? On combining the multiliteral and multiperspectival. STEM Journal, 19(2), 65-93.

This text below transcribes a hypothetical and 'pataphysical dialogue by a group of interlocutors inquiring into the "what and how" of multimodal, Content and Language Integrated Learning (CLIL) methodology. It builds on a unique research paradigm concerned with combining CLIL and multiliteracies theory in the Japanese tertiary education context (Bradley, 2015; Bradley \& Cole, 2016; Bradley, Hunt, \& Cole, 2017). Synthesizing research on CLIL methodology and multiliteracies theory, the paper simultaneously manifests and explores a dialogic "thinking model" for examining complex philosophical and ethical issues with students at beginning or intermediate English levels. Faced with the Japanese government demand to offer more content courses or content-based-instruction (CBI) solely in English, we explore the potential of a CLIL-inspired multiliteracies approach, analyzing numerous examples taken from actual classroom experiences that illustrate how such an approach can overcome the lack of critical thinking and critical media literacy among students. This paper contributes to research on CLIL (Coyle, 2008; Koike, 2016) by demonstrating the applicability of a thinking model for teachers working with low-tointermediate English. It is presented in a dialogic, 'pataphysical format as a way to question the "point of view" of academic research and indeed to transform the practice of academic writing itself.

\section{INTRODUCTION}

Having students of beginning or intermediate proficiency think philosophically in the

${ }^{*}$ Co-authors: Bradley, Joff P. N.; Cole, David R.; Kennedy, David H.; Cabell, Charles; Poje, Joseph 
English language classroom in Japanese tertiary education on postmodern or poststructural topics might appear an impossibility for some and flatly a waste of time for others. However, this paper contests this self-defeating assumption by proffering a content and language integrated learning (CLIL)-multiliteracies approach to the problem of considering different points of view. Although having students adopt different perspectives seems fraught with difficulties, in this paper the authors suggest ways in which various media and forms of multiliteracies may inspire students to adopt alternative perspectives and to think critically about the world at large and their place within it. For example, how might a particular set of problems be approached in new ways by considering different genders, social classes, ages, colonial subjects and races, identities or viewpoints? How might a particular debate be informed by the perspectives of feminism, lesbian, gay, bisexual, and transgender (LGBT), and of various subcultures and legal statuses? What are the differences between the Western, Eurocentric view of knowledge and Asiancentred or multicultural stances (cultures of the North and South)? To answer such questions, we look at how the CLIL-multiliteracies approach has been applied in a new content course entitled Japanese Society (日本の社 ) at a large private university in Tokyo.

The use of a 'pataphysical dialogue in the paper creates a space that unexpectedly, and perhaps discomfortingly, resists the tyranny of academic assumptions that dismiss any possibility of insight into ways of being and living to be gained from approaches that depart from entrenched methodologies wherein truth is defined a priori as systemic, static, verifiable, quantifiable, and able to be abstracted in ways that allow translation into Big Data, which in turn can be added incrementally to a teleological pyramid of progress upon which rests the academy's claim to authority over universal human knowledge. Through such a claim, the Eurocentric locus of globalization is constantly reproduced in universities throughout the world in ways that facilitate the dismissal and destruction of alternate knowledges, languages, cultures and ecologies. In contrast, the dialogic, peripatetic model applied here focuses attention on the spontaneous, the experiential, the affective, the interdisciplinary, the irreducible, the local and the dynamically communal. If we acknowledge teaching as a series of impossibly complex discrete events that can never be fully directed, designed, controlled or repeated, a state of affairs that might be acknowledged in equally creative ways to expand the range of permitted interactions in scholarly conferences and academic journals; then the turn to the dialogic model allows us to reconsider how spontaneity, creativity and emotion - as well as social position, fragmented, indeterminate experience and scale of perspective - create meaning, shaping our understanding, knowledge and behavior. The use here of the 'pataphysical dialogic model thus puts into practice, or "performs", the multiliteracies approach that is being thematically explored. As should become evident, the ideological space created to take 
into account varying perspectives and structures of knowledge creates at the same time new possibilities for interactions with students of varying English levels and subjectivities. We hope to show that adult university students, even with relatively limited English ability and expression, are capable of grappling with issues that might otherwise be assumed as questions better reserved for higher levels of education.

Despite the theoretical nature of the paper, its significance on English-mediated classrooms in the Japanese university should not be overlooked. As a market-driven model of globalized neoliberal education has risen to a position of dominance around the world, including Japan, an instrumentalist evaluation of learning has led to the shrinking or elimination of any subject matter not easily packaged as a marketable asset of the "global human resources" seen as the desired end products. In Japan, shifting a greater portion of university courses into English threatens to radically reduce the intellectual and ethical demands as well as the cultural content of higher learning. In more concrete terms, this shift results in increasing numbers of students who seldom if ever study history, feminism, psychology, sociology, literature, non-western cultures or non-nationalistic ethics to say nothing of philosophy. Failure to find ways to scaffold abstract thinking into English language education may thus condemn such students to a system of learning that can be expected to produce largely ethnocentric, patriarchal, uncritical and disempowered students passively obedient to institutional and social hierarchies of power who perceive of themselves and others primarily in terms of their latent economic value. Readers are encouraged to find throughout the dialogue alternative practical solutions to such a bleak proposition and prospect.

\section{II. 'PATAPHYSICAL DIALOGUE}

The following conversation took place at a scholarly 'pataphysical meeting in Akasaka, Tokyo on July 10, 2017. It was later transcribed by "B" as the basis for a potential screenplay on the state of foreign language learning at the tertiary education level in Japan. The main characters in the dialogue are as follows:

"A": The likeable, open hearted, "good cop" teacher.

"B": The pseudonym for Joff P.N.Bradley of Teikyo University, Tokyo, Japan.

"C": The irascible "bad cop" critic of experimental, critical pedagogy.

"D": The pseudonym of Deleuze pedagogy expert David R. Cole of Western Sydney University, Australia.

"E": The pseudonym of social semiotics scholar David Kennedy of Nihon University, Tokyo, Japan. 
"F": The pseudonym of Japanese literature expert Charles Cabell of Toyo University, Tokyo, Japan.

"G": The pseudonym of graphic artist and assistant professor Joseph Poje of Teikyo University, Tokyo, Japan.

"A": By Jove, you have changed your tune? You have been looking so glum recently, "B"? What has happened to you?

"B": I have been trying to teach critical media studies and to ask philosophical questions in CLIL classes without much success, banging my head on the proverbial wall as it were, but I had a Eureka moment recently, so I am returning to an idea that I became very much interested in a few years ago, namely the idea of multiperspectivism and scaffolded thinking skills in the language classroom. I suppose I am reacting to what I recently found to be a deficit of explanation as to what scaffolded thinking might entail, especially as presented in Rear's chapter "Scaffolding Thinking Skills through Debate" (Breeze \& Sancho, 2017), where scaffolding appears in the title but is not explored in any concrete detail whatsoever. There is material out there, such as Laura MacGregor's (2015) work at Gakushuin University in Tokyo but alas it is fragmentary. Sadly, in the Japanese context, a conspicuous lacuna haunts the practical aspect of scaffolded thinking in the CLIL classroom.

"A": A Eureka moment? How intriguing! Care to explain?

"B": Indulge me. I shall first introduce a CLIL module for a new, administration-led university elective on global Japanese studies held in the 2017 academic year at a private university in Tokyo, Japan. The student demographic had 30 registered students, two thirds Japanese and the rest from other Asian countries. Employing a hybrid methodology of CLIL-multiliteracies and designed to develop students' higher-order thinking skills (techniques and strategies) through the use of scaffolding techniques, lessons aimed to increase students' critical media literacy in ways that would enable them to better comprehend multiperspectivism and cultural difference. The course asked students to confront two philosophical and epistemological questions regarding 1) access to the whole "truth" and 2) the significance of the position of the subject (whether the Japanese subject, the foreign subject, the female subject, the illegal subject, invalidated subject or other formations). I wanted the students to appreciate different and changing subject positions and points of view (socially, culturally and personally). The problem was that teaching this skill in the traditional argumentative fashion (a single discursive essay) proved nigh impossible. I was forced to rip up previous methodologies on problem-solving strategies 
and "go multilateral and multilateral" as it were. I collated "non-argumentational discursive forms" and materials to present a philosophical idea linked to critical media literacy. This is what I call the scaffolding of thinking skills.

"C": "Go multilateral and multilateral"? I have no idea what that means, and it sounds profoundly difficult. Moreover, I am unaware of the difference between the scaffolding of critical thinking skills and the scaffolding of argumentation.

"A": May I interject something at this juncture? You are an exponent of the CLIL approach to language learning, "B"? This I take to mean the interweaving of content and language, or the passage from studying English to studying in English. Would I be right in thinking that? Could you enlighten us all on this and how it works with multiliteracies?

"B": That is indeed true. I am interested in how to best use multiliteracies (Cole \& Pullen 2010; Elsner, Helff, \& Viebrock, 2013; Pullen \& Cole, 2010) in the CLIL-led language classroom in Japan (Bradley \& Cole, 2016; Bradley, Hunt, \& Cole, 2017). I wonder if you scholars might offer some critical advice and response regarding this model.

"A": We shall do our best.

"C": What is this task upon us? Critical media studies? What's that? Why teach such a subject in an English class in a Japanese university? I already see manifold problems with this approach. From which perspective—linguistic or literary-are you responding from?

"B": Having students think philosophically in the foreign language class in Japan with respect to postmodern or poststructural issues might appear nigh impossible for some or a waste of time for others. However, I want to contest this view by proffering what I call a CLIL-multiliteracies and multiperspectivism approach to the problem of considering different points of view. I wanted the students to clarify the nature of a central problem (can we know the whole?) and to evaluate the reliability of information (what is fake news or constructed documentary views?)

"C": May I ask why?

"B": Why? You might well think that we all have the innate skill to be able to reason and think about the lives of those who are not of our own group, class, gender, nationality, age, and so on. You might think it is commonsense and unnecessary to teach. Yet, I have found it to be otherwise, as undergraduates increasingly appear to lack the conceptual knowledge 
to understand different points of view, to empathize as such, or to think beyond the linguistically ingrained binaries of self and absolute other, that is to say, the Japanese and the forever foreign. Innovative lesson plans consequently are necessary to challenge such parochial forms of thinking, which often migrate unconsciously to the target language. Although at first glance and for the most part, having students adopt different perspectives (feminism, post-colonialism, classism and all the other isms) seems fraught with numerous difficulties, I have tried to set out a critical media and multiliteracies approach to the problem at hand, suggesting some ways in which various media and different multiliteracies (mise en abyme in art, TV commercials, film, political cartoons, film, documentaries) may inspire students to adopt alternative perspectives, importantly to be free to do so, and to thus think critically and laterally about the world at large. The playfulness of adopting subject positions of course is a form of lateral thinking and has some basis in Edward de Bono's work on the six thinking hats (1985). In terms of adopting different subject position, how might different genders, social classes, ages, colonial subjects and races, changing identities and viewpoints approach a particular set of problems? How might the perspective of feminism, lesbian, gay, bisexual and transgender (LGBT), different subcultures or legal statuses inform a particular debate in Japan regarding marriage, racism, exploitation? What are the differences between a Western, Eurocentric view of knowledge and Asian-centred or multicultural stances? Is this division no longer valid? How stable are these received identities and distinctions? How might a fluid or fragmented sense of identity better explain the current realities of Japan and the world we are living in at present? I must admit I have come up against numerous theoretical cul-de-sacs in this pedagogical task but I continue to challenge colleagues and students alike with the question: Is it possible to understand the whole?

"C": By Jove, that is a lot to take in all at once; it definitely needs unpacking, but I admit it's thought-provoking. How do you start to teach such a thing?

"B": I have been inspired by Nick Sousanis, the graphic artist whose dissertation was set out entirely as a graphic narrative. Are you aware of it? It is now published as Unflattening by Harvard University Press. In it Sousanis says the following remarkable thing: "Nothing changed, except the point of view - which changed everything" (Sousanis, 2015, p. 33). I was most intrigued by this idea. Here is the page that got me and the students thinking in a new way $<$ Figure $1>$. 
FIGURE 1

Unflattening (Sousanis, 2015, p. 33)

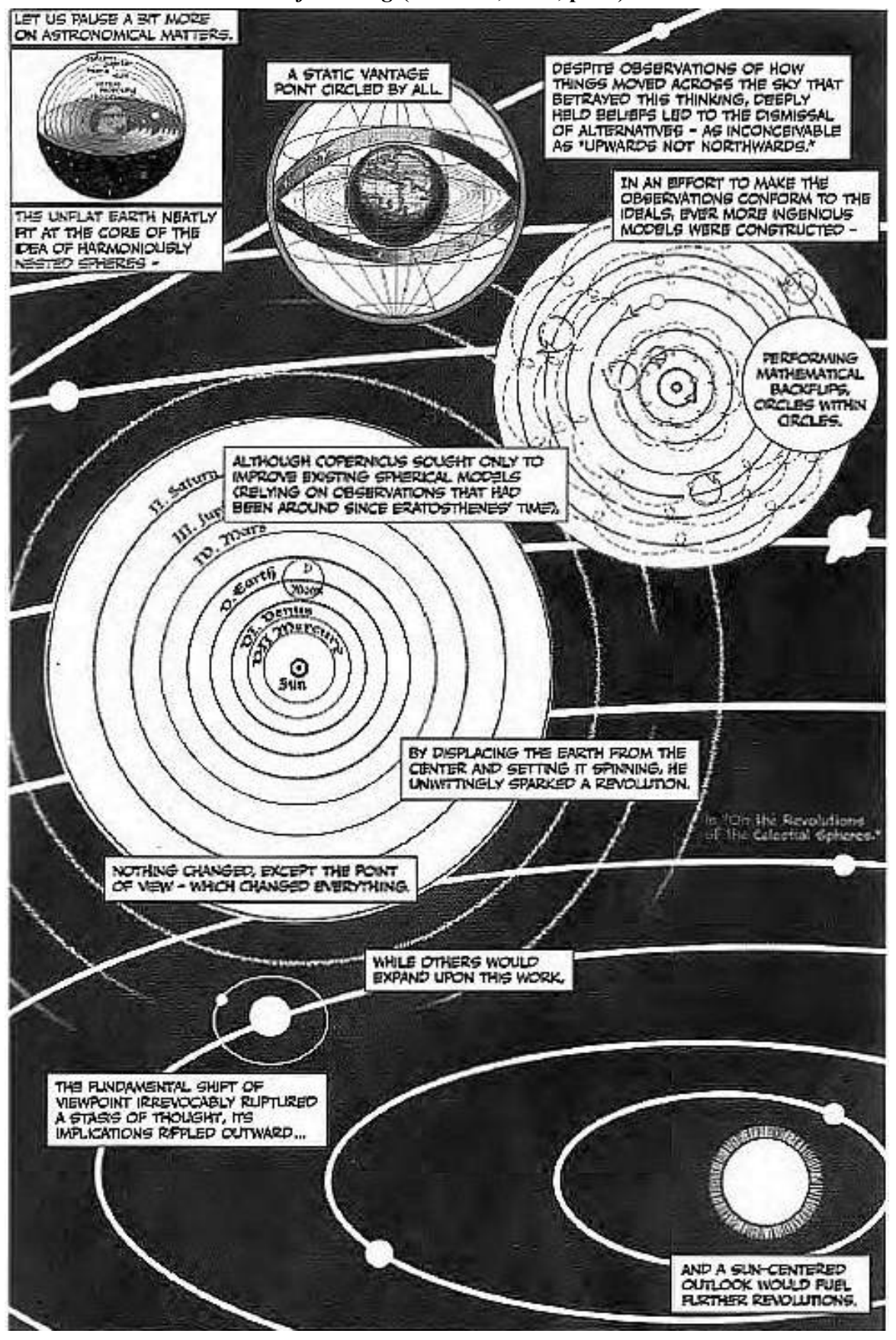


Sousanis has explained to me his rationale for engaging with Deleuze and Guattari. He writes: "I can say I found Deleuze and Guattari's ideas resonated well with how I was thinking about comics and the way they could hold separate fragments together in something cohesive (something comics theorist Thierry Groensteen discusses in his work), and at the same time, I found the difficult nature of their writing as potentially ideally, suited for comics. That is, they are talking about rhizomatic structures and doing so in an inherently non-rhizomatic form, whereas comics could let them make the connections in a more natural way (comics support fragments and connections). I tackled very little of their work, but I like the idea of addressing it deeply through the form and seeing where that goes" (private communication).

"F": The Copernican Revolution is a great example of how the warp and woof of our lives are shaped by the point of view we adopt. To take a case from Japan in the 1940s, novelist Sakaguchi Ango (1947/1990) referred to how fixed perspectives can control us through "the march of history" (p. 93). Academics nowadays might favor an expression such as "dominant discourse", but it is basically the same thing. Ango felt that he and other Japanese regained their humanity when defeat at the end of WWII shattered their adherence to a belief in self-abnegation under the Emperor system. He was skeptical that the Japanese, or any humans for that matter, could live for long without constructing some dominant perspective that would control the thoughts and behavior of members of society. Yet he also appeared to hold out hope that we could resist social control by fully embracing our humanity.

"C": You lost me there!

"F": OK let me help. Please imagine. If you travel through time or space or history, or just look around you, you'll encounter countless people dressing, speaking, behaving and thinking in ways that you would never emulate. Why? Because you're (fill in identity position here such as a "proper lady", "professor" or "German"). Without realizing it, you've allowed codes of belief and conduct that adhere to your identity position to curb your ideas and behavior in ways that rule your life.

"C": Well, what if I'm happy with my identity and don't want to dress like some 19th century cowboy?

"F": That is actually not a bad state to be in because, as you're undoubtedly aware, philosophers and theologians alike often remind us that we cannot love others unless we first love ourselves. Media scholars, on the other hand, 
warn us that much advertising is designed to make us feel anxious and insecure; so if you're happy, you're ahead of the game! Even those of us who find a way to be happy with who we are, however, must heed the ethical demand to listen to others.

"C": Can you walk that back a little and explain what you mean by an ethical demand?

"F": Just what I was getting to. As we come to greater understanding of how we are shaped by our personal history, our family, our class, our gender, our culture, our community, our ethnicity and our sexual orientation, we realize that we see the world differently from others. The closer our identities approximate to what I have called the dominant discourse of our society, the more power accrues to us and the more difficult it becomes for us to listen to and acknowledge the voices of minorities. Maintaining a sense of difference from them may be a key psychological mechanism by which we justify to ourselves our relative privilege. When we fail to heed their challenges to our dominant perspectives of the world, however, we unknowingly add to their oppression by sustaining hierarchal systems that ignore their suffering or contribute to it.

Let's take a look at a couple of examples to help clear things up. Consider the case of an educated, wealthy white American man who lives comfortably in New York City. Can he hope to understand without tremendous effort the perspectives of an American Indian family in North Dakota protesting an oil pipeline being built across their traditional homeland? The man may invest in the corporation that's destroying their community. Unless he's made the effort to hear their voices, he won't notice or, even worse, he won't care. To change location, consider a man in Tokyo who enters into a discussion among Japanese girls about the experience of being groped on trains. Unless he makes a similar effort to understand their perspectives, he may focus only on the chance that someday he may be falsely accused. He may fail to educate his son on the irreversible trauma often suffered by those who are assaulted, or worse, he may casually engage in surreptitiously molesting a woman himself when he feels he won't be uncovered or that she won't dare report him. Without striving to listen deeply to what people in different social positions tell us, we may end up harming not only them but ourselves as well.

"C": How so?

"F": We live in a time of globalization when financial structures are endowing corporations with the ability to produce goods as cheaply as possible and sell them around the world with few or no regulations. The public sphere is being privatized, corporations are paying fewer taxes and the financial sector is being deregulated. The point I am trying 
to make is that this economic system, which results in extreme inequality, would not be possible if we actually grasped the perspectives of those whose lives are destroyed by it. What's more, we are not only destroying the lives of people around the world, we are destroying our very own planet. The belief that we can persist in a system that brings incredible suffering to great masses of people if only it brings wealth to the few is dooming us. Now, more than ever we need to see the world as Copernicus saw it and when that happens we will have no choice but to act, to resist!

"A": That's exceedingly interesting but let me return to graphic narratives for a moment to clarify your point. I know Sousanis's work too. I see what you mean now. Could you say this is a paragon of multiliteracies?

"C": Multiliteracies? I am lost again. Do explain.

\section{MULTILITERACIES}

" $\mathrm{D}$ ": Let me step in here. Multiliteracies is a theory of literacy (i.e., reading/writing/speaking and listening) from the 1990s, that takes into account the changing nature of literacy, given, for example, the emerging digitally mediated modes of communication. Multiliteracies is a form of semiotics, that is, it analyzes the signs and symbols of this new communications environment, and relates it to pedagogy and the design of social futures.

"B": I do believe Sousanis's work is a good example. It has a very interesting Deleuzian perspective regarding the sense of change and the notions of perspective and event $<$ Figure $2>$.

"D": From the multiliteracies perspective, this is an example of visual literacy, with its own set of symbols and signs involved with understanding how this visual literacy works. However, Sousanis goes further than merely presenting an example of visual literacy. His work attempts to analyze the ideas from within, something that one can do as a comic strip creator. As such, one could say that this work is philosophical, and specifically, Deleuzian. 
FIGURE 2

Unflattening (Sousanis, 2015, p. 38)

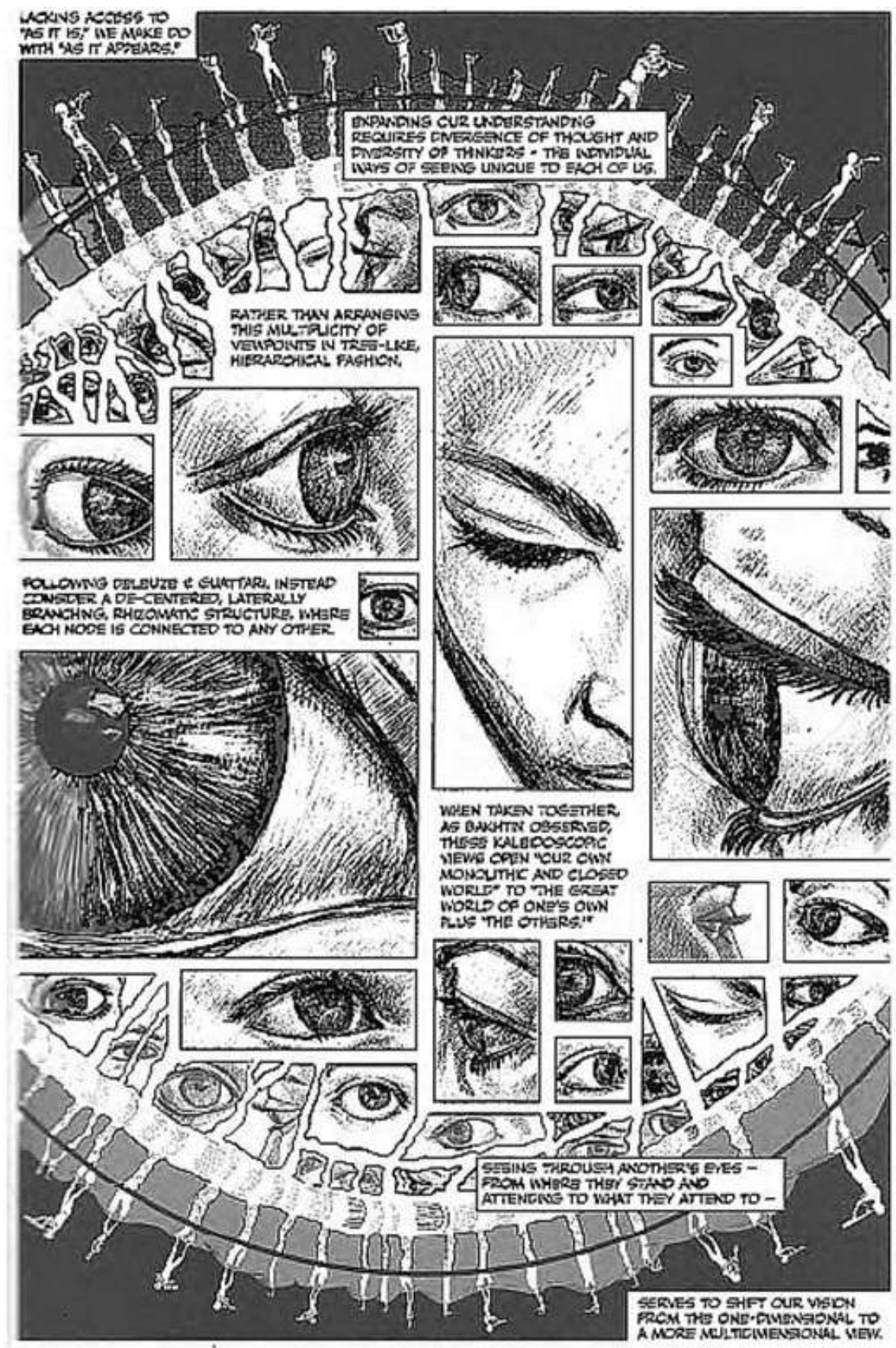


"C": A Deleuzian perspective? I am lost again. Could you unravel some ideas briefly?

"D": The Sousanis cartoon goes beyond a mere representation of ideas or semiotics of visual literacy. He deliberately plays with the format of the comic strip, the ideas that are being presented, the perspective as to who is doing the drawing, and the possible interpretations of his work. This philosophical approach to representation most closely adheres to a Deleuzian position. Though this position involves too many parts to completely explain here, it is worth mentioning my multiple literacies (Masny \& Cole, 2009; Masny \& Cole, 2012) and cinema (Cole \& Bradley, 2016) work in this area. Both of these projects attempt to bring educational approaches closer to the chaos of nature, and move away from the predominantly human-only bias in education. Similar to the work of Sousanis, this expansion of perspectivism in education is a rational attempt to make us think anew.

"C": How does this apply to the language classroom and the CLIL classroom in Japan in particular, "B"?

"B": I am interested in how to teach complex content which stimulates and motivates students, literally to the point of shaking them out of their media-intoxicated slumbers and stupor. I am opposed root-and-branch to the teaching of the lowest common denominator of content, that is to say, the content which reinforces all manner of racist, national and sexist stereotypes, and which stops students from thinking critically. The philosopher Bernard Stiegler (2015) captures the Zeitgeist and calls this the proletarianization of knowledge. I thought long and hard about the question of their subjectivity or, let me put it like this, what the "production of subjectivity" (Guattari, 2013, p. 1) might signify as a means to that end. We also invoked here Deleuze and Guattari's (2011) concept of the line of flight, which can be described as a connection that occurs between self and others (Deleuze \& Guattari, 2011).

But I had to think of how to scaffold this critical thinking approach in the CLIL class. I have been considering how scaffolding critical thinking strategies can motivate and enhance language learning. The question arises: How can we better balance scaffolding language, complexity and cognition, the latter of which I take to mean the thinking skills used to understand content (solve puzzles, reflect on learning) - (Bradley, 2015; Bradley, Hunt, \& Cole, 2017)? Given the breakdown in the understanding of different conceptual strategies (feminist, post-colonial, post-modern) by the students, in the end I thought it proved vital for me to scaffold and prioritize cognition. However, because of time and the purpose of the course itself which was to teach content (modern Japanese society through 
documentary and film - both historical and contemporary), I could not examine at length theoretical concepts such as psychoanalysis, post-structuralism, post-modernism, cultural theory, post-colonial theory-concepts which can be used to effectively address issues such as identity and subjectivity. I had to rethink the use of non-argumentative forms. So my goal was to design conceptual scaffolding techniques and strategies in the CLIL classroom.

"C": I am still struggling, could you say a little more about the connection of CLIL and multiliteracies and how it works in practice?

"B": I believe the teacher should provide multimodal input in the CLIL class as much as possible because this is a means to foster different learning styles and skills in language learning. This aspect of multimodal aids the development of new multiliteracies. The use of texts, video, commercials, documentary, film, poetry, Japanese Ukiyo-e（浮世絵）, graphic novels and cartoons acted as a kind of input-scaffolding. For the students to begin to discuss critically the role of the contemporary media (authentic materials) demanded a scaffolding of concepts to enable them to comprehend the input. In the CLIL class we used an array of tasks (translation from Japanese to English, analyzing poetry and Ukiyo-e and their semantic connections, analyzing the question of fake news through TV commercials), to bolster higher-order thinking skills and authentic communication in different interactive formats (solo work, pair work, group work). The nature of the output was decided collectively as a class, with some students opting for poster presentations, others for workshop-style group activities, quizzes, video or standard PowerPoint presentation. In addition, I required a compulsory English composition. Once the tasks were agreed upon, the nature of output-scaffolding had to be designed as well. This proved relatively successful in that the methodology fostered academic language proficiency as well as learner autonomy, development of learning skills and collaborative engagement. The use of TV commercials for example, a key component of the CLIL classroom, gave the students access to authentic language while encouraging critical thinking and higher-order cognitive skills. Finally, the CLIL class on different points of view was meaningful in the way it raised issues about the complex, media-inflected lives of the students themselves.

"C": Goodness gracious me. The class sounds very experimental.

"B": Perhaps so. However, I am of the view that effective CLIL classes functioning in a new paradigm of teaching and learning have to be experimental and thoroughly creative. Otherwise they may struggle to meet the design goals. On this point, I took inspiration from Michael Peters, a philosopher of education, whose embrace of "non-argumentational 
discursive forms" and remarks on Ludwig Wittgenstein's style(s) of thinking promoted me to tear up the format of the content class and start again by approaching language learning and critical thinking questions from a pedagogical point of view. I have the quote in mind to hand. It is from a chapter entitled 'Philosophy as Pedagogy: Wittgenstein's Styles of Thinking', in which Peters (2013) contends: “[Wittgenstein's] styles are... essentially pedagogical; he provides a teaming variety and vital repertoire of nonargumentational discursive forms - pictures, drawings, analogies, similes, jokes, equations, dialogues with himself, little narratives, questions and wrong answers, thought experiments, gnomic aphorisms and so on - as a means primarily to shift our thinking, to help us escape the picture that holds us captive" (pp. 12-13).

I was taken aback by the way he suggests the necessity to shift thinking, so as to escape "the picture that holds us captive". This resonated a great deal with the graphic representations of Sousanis. I think it is necessary to combine the theory of teaching and the acquisition of English with the reality of its practice in the classroom. That would be the applied linguistic approach, I suppose. Using multiliteracies and authentic materials such as film, TV commercials, as well as graphic-form books and cartoons would be the literature aspect, albeit in a non-argumentational form.

"A": I am aware that Wittgenstein is reported to have said that "a serious and good philosophical work could be written that would consist entirely of jokes" (Malcolm, Wittgenstein, \& Wright, 2001, pp. 28-29). One imagines that this is consistent with Sousanis's interesting idea that Deleuze and Guattari's writing lends itself to being presented in comic, graphical form (Sousanis, 2015, p. 161).

"B": I wasn't aware of that. That's an interesting point.

"C": I have some further questions. I would like to know how to do a CLIL class. It is important to address here the educational and pedagogical implications for language learning and teaching through multiliteracies media. Please explain in concrete terms what you do in your multiperspectivism class because at the moment this is all terribly abstract!

"B": Allow me to list the multiliteral resources I have used to demonstrate the necessity to adopt different points of view. Given my location in Japan and teaching a content class on Japanese society we began the thinking process with the Ukiyo-e print of Hanabusa Itchō (英一蝶, 1652-1724). It is typically called "Blind monks examining an elephant" (衆韾探象之圖). This I used to entice students into thinking about its meaning (<Figure $3>$ ). 
This was latter coupled with the poem "The Blind Men and the Elephant" by John Godfrey Saxe (1816-1887), adding an important comparative cultural and historical perspective. We looked at how this story is expressed in a wide variety of literature in India and the Middle East.

FIGURE 3

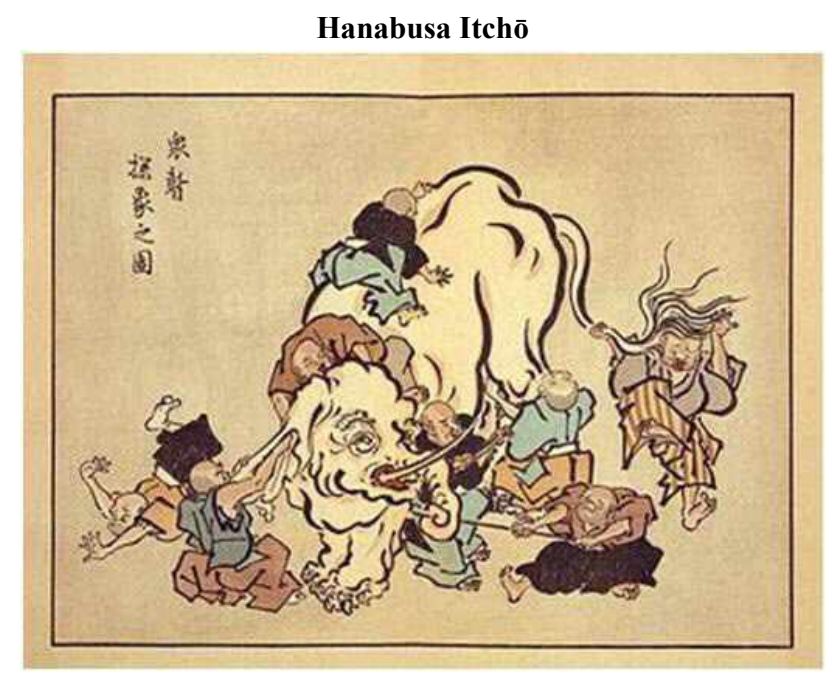

"A": I am familiar with this tale: it is about blind men each having a dogmatic opinion and particular perspective on the nature of the thing before them which they cannot see. It concludes with a reflection on differences and unity of parts and the whole.

"B": Again using non-argumentational discursive forms in Wittgenstein's sense, from here we addressed the questions "What is the nature of postmodern media?" Concretely undertaken, we used the following award-winning TV commercials made for The Guardian newspaper: 1) Points of View (Weiland, 1986); and 2) Three Little Pigs (Ledwidge, 2012). In terms of the first and before showing the commercial, I showed the students 20 frames taken from the commercial. This is what I designated a movie map (Bradley, 2015). Students created meaning from these frames, discussing the meaning of the flow of images, and working on the tense (this is a scaffolded language exercise). In any case as the TV commercial is for the most part silent it gave the students ample opportunity to generate language and meaning. Students then discussed the representation of youth in the scene and the unconscious assumptions and prejudices which are manifested by the frames, which we later applied to different contexts. "G" has some 
comments on how cartoons and graphic representations can help us to see things differently. He redrew Weiland's advert in graphic form (see $<$ Figure $4>$ ).

\section{FIGURE 4}

The Guardian, Points of View by Joseph Poje (2018)

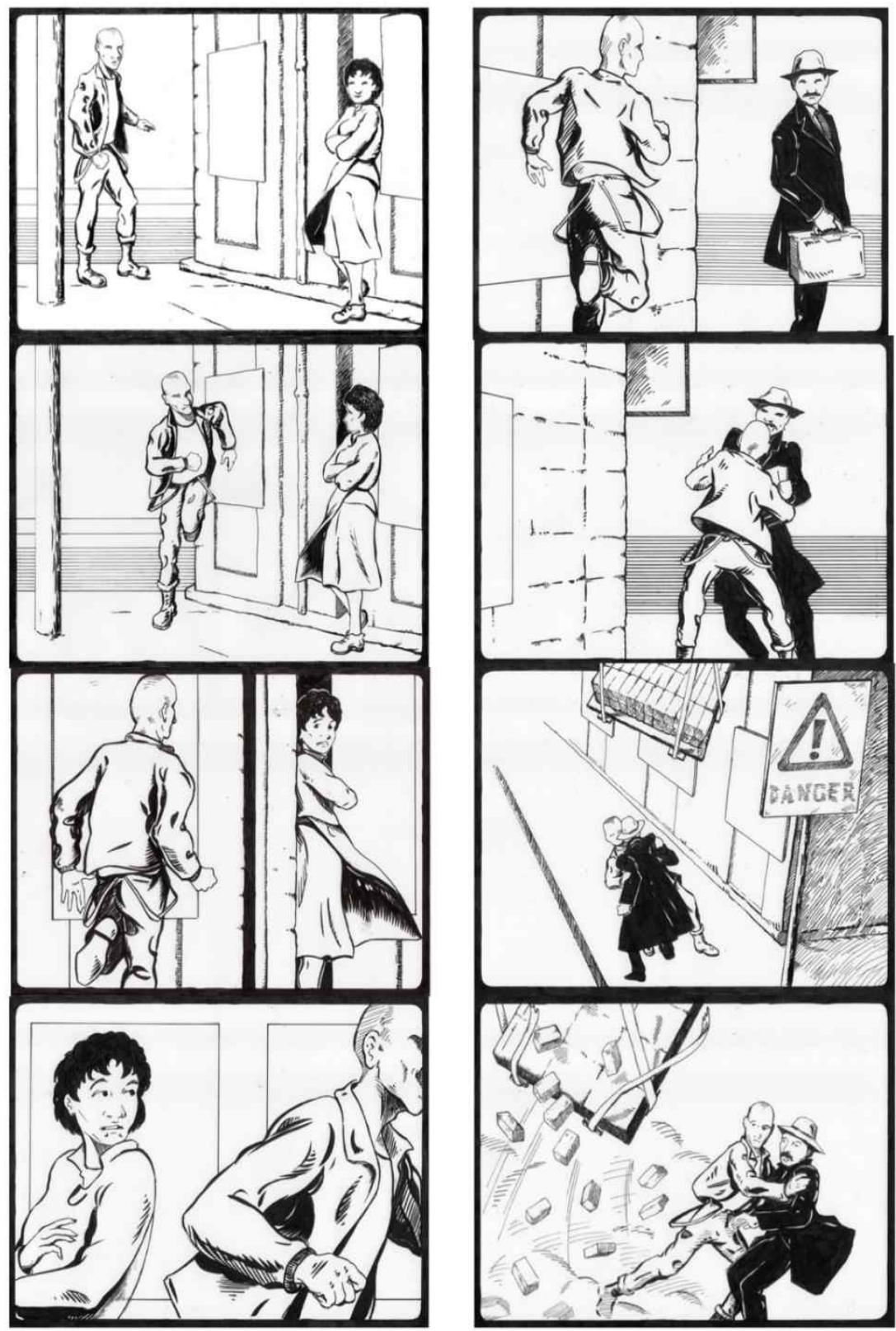


"G": Thank you for inviting me to the discussion. My contribution is an attempt to create a graphic representation of the Points of View commercial. My first attempt was to approach the drawings as a storyboard for a scene in a movie or TV program. I tried using the original 20 frames " $\mathrm{B}$ " used in his lesson to create 8 drawings and condense the story but keep it as true to the commercial as possible. I copied the same three camera angles as in the commercial. It wasn't until I was halfway finished that I realized I was creating a storyboard for something that had already been storyboarded! I wasn't bringing anything different to the story except that it was in pen and ink.

After watching the commercial again, I decided to add some closeups and different camera angles. In panel three I portray the woman reacting with a bit of fear in her expression and in panel four relief and curiosity after the skinhead runs past her. In the final image the intent of changing the angle from above the businessman is to show a closeup of his face realizing the danger that he was saved from.

Using cartooning also places the focus on the central elements of the story: the characters, setting and props (the falling bricks). The backgrounds of the street, buildings, and cars are simplified or removed to focus on the story. The graphic representation shows the same narrative as the video but gives the observer a more involved experience in the characters' experience. The artist could also make the images more simplified and still convey the same experience; the observer would still be invested in the story.

"B": Wow, that's incredibly fascinating. So cartoon representations can fathom emotions in a different way than moving images can.

"A": Could you explain a little more about the commercial?

"B": The commercial features a skinhead who appears intent on seizing a man's briefcase. The change of the point of view of the camera reveals that he is in fact trying to rescue the man from falling bricks. The intent of the commercial is to act as a metaphor for understanding the truth, for getting at the truth. As for the language learning, I translated the statement (see appendix) at the end of the short commercial into Japanese and the students translated it back into English. Before comparing the translation with the original, we did a listening exercise using the following voiceover dialogue: "An event, seen from one point of view gives one impression. Seen from another point of view it gives much a different impression. But it's only when you get the whole picture, you can fully understand, what' going on." 
We then discussed the question: is it possible to understand the whole? This provides the philosophical context of the class in conformity with the class goals. Updating the exercise on different points of view, I used the 2012 commercial Three Little Pigs again by The Guardian. In this commercial the image, text, and audio all operate on an equal level, which reinforces the necessity for a multiliteracies dimension to language learning. As the story itself is different from the original, students were compelled to address wider social, economic and political issues in the U.K. regarding the housing mortgage crisis and fraud. In the clip, the different points of view raised across languages by users of online media (Facebook, Youtube and traditional media outlets) with different identities allowed the students to raise questions about the creation of "fake news" or simulacrum of the truth (fake news was the word of the year in 2017 according to Collins Dictionary). I again raised questions about access to the "whole truth". To undergird this point, I turned to Alfred Hitchcock's comments on the use of montage images as a way to create different meanings (Merton, 2009) and of course the majestic The Birds (Hitchcock, 1963) to explore the bird's-eye shot or gaze. Moreover, as our focus was on Japanese film and documentary during the course, we addressed the Rashōmon effect.

"E": The Rashōmon effect? What is that?

"B": This effect occurs when the same event is given contradictory interpretations by different individuals involved. The effect is named, of course, after Akira Kurosawa's film Rashōmon（羅生門; Kurosawa, 1950), in which a murder is described in four mutually contradictory ways by its four witnesses (The events of the film are based on the short story In a Grove by Ryūnosuke Akutagawa). Similar to Weiland's Points of View commercial, this proved heuristic in explicating the motivations, mechanisms, and occurrences of reporting an event. It other words, it addresses the essentially contested interpretations of events. Anderson (2016) describes it as "the naming of an epistemological framework - or ways of thinking, knowing, and remembering-required for understanding complex and ambiguous situations" (p. 250). There is also the film animation adaptation of the parable-The Dermis Probe (Williams, 1965). In the animation, inspired by a tale found in the Sufi collection of rhymed spiritual couplets known as Masnavi (Rumi, 2001) by Persian mystic Rumi (ca $13^{\text {th }}$ century), a team of scientists debate the nature of an unknown material. Rumi's poem itself is a retelling of a story found in Enclosed Garden of the Truth (ca $11^{\text {th }}$ century) by philosopher poet Hakin Majdud Sanai of Ghazna (ca $11^{\text {th }}$ to $12^{\text {th }}$ century), which focuses on the mechanisms of learning and possibilities for cultural understanding (Sanai, 1910). There are many other examples of this idea too that we can find in modern science, and in Buddhism and Hinduism. In science there is Werner Heisenberg's famous view that "We have to 
remember that what we observe is not nature in itself, but nature exposed to our method of questioning" (Baggott, 2011, p. 109).

"A": We have been talking about different points but I have a question on how to get at the truth "behind" multiple points of view. How would you demonstrate that as a form of scaffolded thinking?

"B": As you know I have been using Harold Pinter in my classes. Pinter (2005) sets out his attitude on telling the truth in his Nobel Prize speech "Art, truth and politics". We hear the insistence that language is a kind of regime of order-words, cliché and hearsay, often deployed to keep thought at bay and to maintain the status quo (Bradley, 2014; Chiasson, 2017).

Thoughts and counter-thoughts happen but language hides them from exposure. It is a question of truth and the maintenance of power. The public, for Pinter, are acquiescent in the maintenance of this status quo. What surrounds us, he insists, "is a vast tapestry of lies, upon which we feed" (Pinter, 2005, p. 10). He concludes his speech by discussing the role of the writer, suggesting the metaphor of the mirror. He writes: "When we look into a mirror we think the image that confronts us is accurate. But move a millimetre and the image changes. We are actually looking at a never-ending range of reflections. But sometimes a writer has to smash the mirror-for it is on the other side of that mirror that the truth stares at us" (Pinter, 2005, p. 21). Again this was consistent with the CLIL class goals of appreciating different points of view through and by using authentic literature.

"C": How did you demonstrate this in multiliteracies terms?

"B": We have used Pinter's short dialogue entitled Apart From That (Pinter, 2014), made shortly before his death, the BBC radio play Mountain Language (Pinter, 2014) and the original text as well looking at his Nobel prize speech.

"C": Thank you for the detailed explanation but let us return to the meta-questions that were raised in terms of the TV commercial's effect on the students.

"B": From here we discussed the decline of free speech in Japan. How fake news is verified or contested, the manipulation of the public at home and abroad and the dangers of fake news, propaganda in documentaries. We examined U.S president Trump's use of Twitter. In terms of the changing contours of stereoscopic thinking, we looked at numerous 
multiliteral forms. For example, the Esper Photo Analysis scene in Bladerunner (Scott, 1982).

"C": Could you possibly explain further?

"B": I cannot recall in their entirety many of the conversations I had when I was a university student but there is one which sticks in my mind. It was speaking to a chemistry student who was indifferent to everything other than passing his course. Watching Bladerunner on video, we got into a conversation about the Esper Photo Analysis scene. Because he was a scientist I asked him innocently if such a technology existed. He replied negatively and said that it would never be realized. Those words uttered in 1991 seem somewhat off the mark nowadays as we can perform such rudimentary tasks of microscopic analysis on even the simplest photo-editing software on our PC or smartphone. I discussed this view with my students and this anecdote helped again to germinate questions about perspectives and points of view influenced by changes in technology, which can reimagine things otherwise, or destabilise and reverse the structures of relationships we adopt unthinkingly. We looked at Eames and Eames's (1977) short documentary, Powers of Ten, and this led to questions of the transphenomenal and metaphysical expressed in science fiction films like Fantastic Voyage (Kleiner \& Fleischer, 1966) the American science fiction film directed by Richard Fleischer and written by Asimov, Kleiner, and Klement. As you may know, Powers of Ten explores orders of magnitude or the relative scale of the universe. The universes that are explored are cosmic and microscopic in scale as both points of view look out to the heavens and inward of the human body until it reaches a single atom and the quarks observed. At micro and macro levels, Powers of Ten explores the Copernican revolutions of scale in human thinking, which underscores what "F" was arguing for. It demonstrates that earth-centred or anthropocentric thinking is just one mode of thought in a universe which for all intents and purposes has no centre.

"C": OK, I am beginning to get this. Is there any theory which lies behind this regarding the sense of the production of subjectivity?

\section{PRODUCTION OF SUBJECTIVITY}

"A": Might I interject at this juncture? Yes, there is indeed some very excellent work in this area. I would guide you to the recent chapter by Derek Woods on zoom and scala entitled "Epistemic Things in Charles and Ray Eames's Powers of Ten" (Clarke \& 
Wittenberg, 2017). Woods writes of the movement of the zoom and scala across the textual. This, I think for "B"'s purpose is a kind of textual multiliteracies: across cinema, graphic forms, visual literacies and media technologies. This, Woods says, shapes the "collective possibilities of imagination". His comments with respect to Felix Guattari are very interesting. He writes (Clarke \& Wittenberg, 2017) "The broad archive of texts that use smooth zoom and scala to represent movement across scales constitute a process of subjectivation, in Felix Guattari's sense of shaping the collective possibilities of imagination in relation to social assemblages and the nonhuman environment. As these texts spread through the populations they reach, they interact with human bodies to create new forms of subjectivity. Subjectivity in this sense distributes across the media technologies and aesthetic forms that support its development across time. How we interpret it depends on the relation of text and epistemic thing" (p. 71).

Woods argues that the movement across scales constitutes a process of subjectivation. I suppose for our purposes this means that students can constitute a different point of view and different identities through changes in zoom and scala. They can generate alternative conceptual maps and recognize the existence of alternative maps. From this they can make changes to ways of thinking, which they unconsciously inherit through language and culture. The process demonstrates the contingency of one's own map of the world.

"C": By Jove, that is interesting. I wonder if the mise en abyme is applicable here.

"B": Yes, I think you are getting it. I have used a postmodern cartoon entitled "I don't get it" $<$ Figure $5>$ to demonstrate how the mise en abyme raises questions of where the original point of view begins and ends.

As you know mise en abyme is a literary concept (in our case pictorial) denoting a part of a work that resembles or is identical to the whole. It makes a double of the work within the work. In the cartoon's case, this double is reproduced ad infinitum. In the classroom, it allowed students to ask questions about the play of mirrors and multiple identities, and of virtual selves-images within images, stories within stories - again a very postmodern motif. The cartoon is very effective in provoking students to think about their relation to the cartoon and their perspective, location and situation. 


\section{FIGURE 5}

I Don't Get It

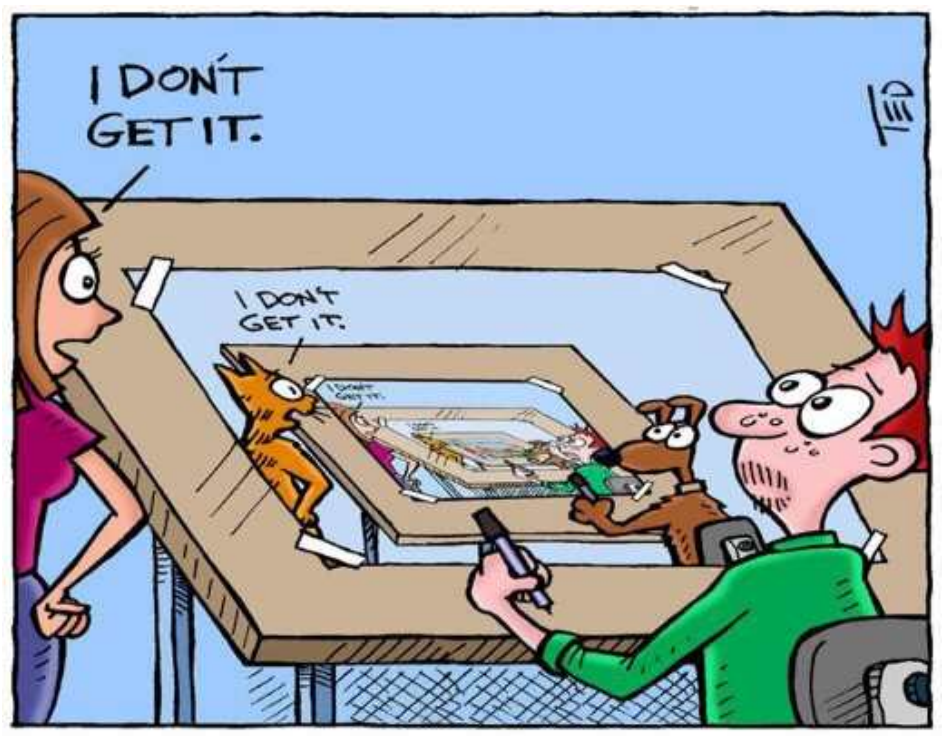

"A": By Zeus your right; that's a thought-provoking way to raise questions about the role of the active, decentred, postmodern viewer as a participant in the narrative and creation of meaning. But one thing conspicuously missing from this is - semiosis.

\section{SEMIOSIS}

"C": Semiosis? Just when I thought I was getting on top of things. Not another word I don't know. Help!

"B": Ah well, Professor "E" might help us out. I know he has been listening in. Do you have a moment to explain how semiosis might work here?

"E": I do. One of my ideas is to have students create meaning in a semiosic way through a kind of puzzle architecture - that is, they evaluate a number of artifacts in different modalities to address questions of multiperspectivism. Students learn to piece their own semiotic puzzle together, compare with other students, and then reassemble. And then do it again. It's a kind of archaeology of contemporary society, if you will. There never is a single "correct" analysis. This is a really stimulating way of integrating authentic content from a variety of sources into a "language learning" classroom. 
"B": You said semiosic, not semiotic. Care to explain?

"E": Semiosis has to do with meaning-making. It is a term coined by the American pragmatist philosopher Charles Sanders Peirce, who posthumously became recognized as one of the founders of the field of semiotics, or the study of signs and their significance. The other figure, who is somehow better known, was Ferdinand de Saussure. To simplify massively, Peirce's semiotics differs from Saussure's in his inclusion of an interpretant in the making of meaning. The semiotic object, Peirce would say, is not "as it is", but "as it is to me" (cited in van Lier, 2004, p. 91). So meaning is not simply a static correlation between an object and its signifier, but is in a constant state of flux. The semiotic relationship is first shaped by the person interpreting it, and then further modified by other people through social interaction, which in turn spawns new semiotic relationships. And on and on infinitely. This process is what Peirce called "semiosis", the making of meaning.

FIGURE 5

Dialogically Coupled Signs on the Indexical Plane (Adapted From van Lier, 2004, p. 69)

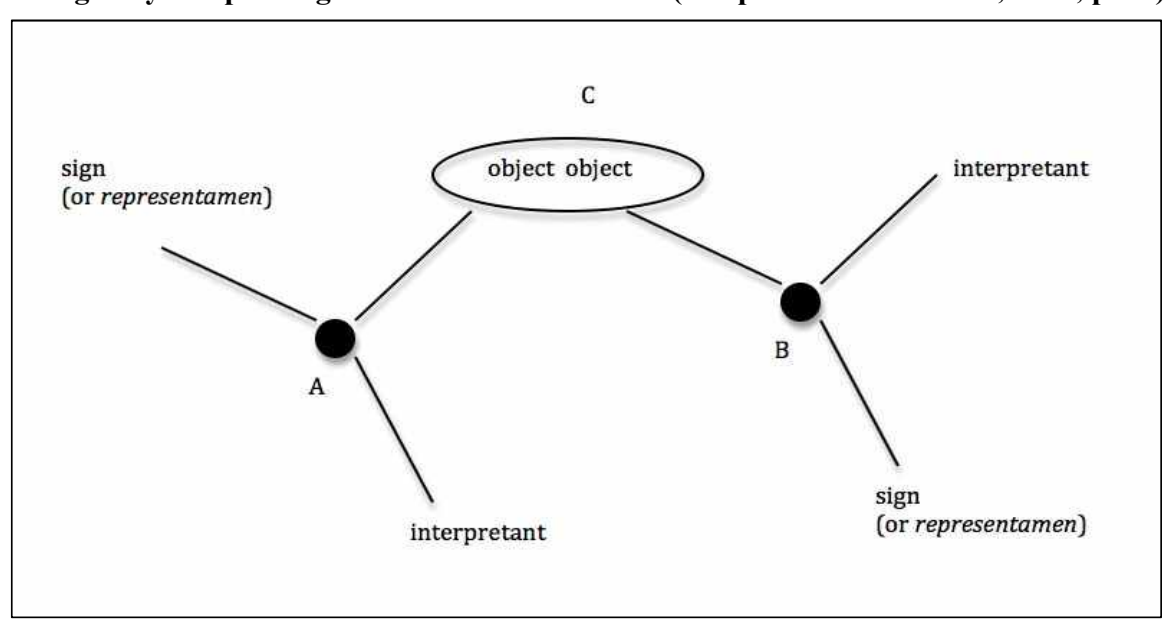

"B": So learning is always up in the air?

"E": Yes and no. In my view, we obviously share (or think we share, which might be the same thing anyway) common ideas about what something means. Without this we would have no way of communicating or creating cultures. This shared semiosis is central even to our phylogenetic evolution. Human civilization is built on these understandings. There's a fantastic little book by Thomas Sebeok (2011) called Signs: An Introduction to Semiotics 
that describes the expansion of this "biosemiosis" into the social realm. Despite such historical continuity, however, and without getting too Derridean about the endless deferral of meaning, we have to keep in mind that semiotics—our understanding of signs-is never a settled matter. It is always and forever under negotiation. And these negotiations are, I think, an essential part of education.

"B": Can you explain more about semiosis and education?

"E": It's pretty simple, really. To understand "the world" is to first understand that the world is made up of myriad interpretations, perspectives, and experiences. Education is the place where these "multinesses" are allowed —or better yet, encouraged— to come up against each other, sometimes in agreement, and sometimes in discord. This is social practice, and it is messy. Van Lier (2004) situates this social process of meaning-making at the "interconnections between the contexts that we create by our own activity and the contexts that are created by others, in which we find ourselves, either by design or by accident” (p. 40). Quite a bit like the conversation we've all been having here, isn't it?

"B": And on that note I think it is time to move to the conclusion.

\section{IN LIEU OF A CONCLUSION}

English pedagogy conducted in Japan by international teachers, who are conspicuously different in ethnic appearance from their primarily Japanese students, is haunted by irony. The apparent embodiment of cultural and linguistic alterity by such teachers inevitably reifies feelings of homogeneous nativism among their students. In other words, their presence as cultural and linguistic "others" reproduces the prejudiced assumptions that they loathe to encounter in everyday life in Japan. The role they are asked to play in the Japanese university is to confirm their ontological status as eternal aliens, detached from everything Japanese and perceived as incompetent in tasks requiring "native" knowledge, language and cultural awareness. Their English instruction renders them invisible residents, unwilling mirrors reflecting feelings of exceptionalism back onto Japanese, effectively closing students off from the multiperspectivism opened up in B's course.

How could one smash such a mirror to bits in Pinteresque fashion, throwing students' received wisdom about national and linguistic identity into doubt and fragmenting the lazily adopted "truths" on which identity positions rest? The 'pataphysical dialogue employed here suggests that the solution does not lie in berating students or arguing them into imaginary submission. "B" rather lovingly spoons out dollops of multimodal honey 
to entice his flies away from their comfort zones before taking them on a non-discursive flight that destabilizes their perspectives, opening up new ways of seeing the world that foreclose previously held viewpoints. Students are led not to a new perspective, but to a new way of thinking about perspectives. To put it differently, multiliteral, multiperspectival learning experiences break down ingrained binaries to produce new subjectivities. Truth becomes contingent in the unflattened world of "B"'s classroom.

Attuned readers will have noted the ease with which the multimodal approach to scaffolded thinking can be applied to English learners of low-intermediate ability and above. Experienced foreign language teachers should have little trouble creating levelappropriate lessons around concrete images such as those found in graphic drawings, film frames, commercials and videos. What is in question, however, is their willingness to embark on such an endeavor. Is higher learning destined to be dumbed down as the Japanese university transfers increasing portions of education into English? This paper has demonstrated that this need not be the case. By deploying scaffolded thinking exercises based on an approach grounded in research on multiliteracies and multiperspectivism, learning experiences that deal with highly complex philosophical questions related to epistemology, ontology and semiotics can be incorporated in classes of students with lowintermediate English skills. Negotiating the understanding of signs should be an essential part of every education, including language education.

\section{REFERENCES}

Anderson, R. (2016). The Rashomon effect and communication. Canadian Journal of Communication, 41(2), 250-265.

Ango, S. (1990). Darakuron [On Decadence]. In M. Yasutaka (Ed), Darakuron [On Decadence] (pp. 91-102). Tokyo: Kadokawa Bunko.

Asimov, I., Kleiner, H., \& Klement, O. (1966). Fantastic voyage. New York, NY: Bantam Books.

Baggott, J. E. (2011). The quantum story: A history in 40 moments. Oxford: Oxford University Press.

Bradley, J. P. N. (2014). Pinter: Held incommunicado on the mobile. Dialogos, 14, 51-81.

Bradley, J. P. N. (2015). Pleasurably bepuzzled: CBI/CLIL and film. Forum of the Center for Teaching and Learning Teikyo University, 2, 19-38.

Bradley, J. P. N., \& Cole, D. R. (2016). On multiple literacies and language learning: Video production and embodied subjectivities. In F. Y. Sim \& M. Brooke (Eds.), ELTWO: Special issue on 5th CELC symposium (pp. 94-105). Singapore: Centre for English Language Communication, National University of Singapore. 
Bradley, J. P. N., Hunt, J. R., \& Cole, D. R. (2017). CLIL-multiliteracies-multiple literacies theory: On the passage from active viewing to active filmmaking. STEM Journal, $18(2), 179-202$.

Breeze, R., \& Sancho, G. C. (2017). Essential competencies for English-medium university teaching. Cham, Switzerland: Springer International.

Chiasson, B. (2017). The late Harold Pinter: Political dramatist, poet and activist. London: Palgrave Macmillan.

Clarke, M. T., \& Wittenberg, D. (Eds.). (2017). Scale in literature and culture. New York, NY: Palgrave Macmillan.

Cole, D. R., \& Bradley, J. P. N. (2016). A pedagogy of cinema. Rotterdam: Sense.

Cole, D. R., \& Pullen, D. L. (Eds.). (2010). Multiliteracies in motion: Current theory and practice. New York, NY: Routledge.

Coyle, D. (2008). CLIL-A pedagogical approach from the European perspective. In N. H. Hornberger (Ed.), Encyclopedia of language and education (pp. 1200-1214). New York, NY: Springer.

De, B. E. (1985). Six thinking hats. Boston, MA: Little, Brown.

Deleuze, G., \& Guattari, F. (2011). A thousand plateaus: Capitalism and schizophrenia. (B. Massumi, Trans.) London: Continuum.

Eames. C., \& Eames, R. (Producers). (1977). Powers of ten: A film dealing with the relative size of things in the universe and the effect of adding another zero [Documentary]. Bucksport, ME: Northeast Historic Film.

Elsner, D., Helff, S., \& Viebrock, B. (2013). Films, graphic novels \& visuals: Developing multiliteracies in foreign language education: An Interdisciplinary approach. Wien, Berlin: Lit.

Guattari, F. (2013). Schizoanalytic cartographies. New York, NY: Bloomsbury.

Hitchcock, A. (Director). (1963). The birds [Motion picture]. Universal City, CA: Universal.

Jarry, A., Edwards, P., \& Melville, A. (2001). Adventures in 'pataphysics. London: Atlas.

Kennedy, D. H. (2013). A social semiotic approach to content-based (language) learning. Dialogos, 13, 97-126.

Kleiner, H., \& Fleischer, R. (Producers). (1966). Fantastic voyage [Motion picture]. Los Angeles, CA: Twentieth Century-Fox.

Koike, A. (2016). Promoting CLIL in higher education in Japan. Journal of Development Studies, 19, 69-76.

Kurosawa, A. (Producer). (1950). Rashomon [Motion picture]. London: BFI Video Pub. Ledwidge, R. (Director). (2012). Three little pigs [Television commercial]. BBH London. Retrieved from https:/www.theguardian.com/media/video/2012/feb/29/openjournalism-three-little-pigs-advert 
MacGregor, L. (2015, November, 14). CLIL: poster presentation. Poster session presented at the 41st Annual International Conference on Language Teaching and Learning \& Educational Materials Exhibition (JALT), Shizuoka, Japan.

Malcolm, N., Wittgenstein, L., \& Wright, G. H. (2001). Ludwig Wittgenstein: A memoir. New York, NY: Oxford University Press.

Masny, D., \& Cole, D. R. (Eds.). (2009). Multiple literacies theory: A Deleuzian perspective. Rotterdam: Sense.

Masny, D., \& Cole, D. R. (2012). Mapping multiple Literacies: an introduction to Deleuzian literacy studies. London: Continuum.

Maturana, H. R., \& Varela, F. J. (2008). The tree of knowledge: The biological roots of human understanding. Boston, MA: Shambhala.

Merton, P. (Producer). (2009). Paul Merton looks at Alfred Hitchcock [Motion picture]. London: BBC.

Peters, M. (2013). Educational philosophy and politics: The selected works of Michael A. Peters. London: Routledge.

Pinter, H. (2005). Art, truth \& [and] politics. London: Illuminations.

Pinter, H. (2014). Apart from that. London: Bloomsbury.

Pinter, H. (2014). Mountain language. London: Bloomsbury.

Poje, J. (2018). The Guardian, Points of View [Original artwork].

Pullen, D. L., \& Cole, D. R. (2010). Multiliteracies and technology enhanced education: Social practice and the global classroom. Hershey, PA: Information Science Reference.

Rumi, J. (2001). The elephant in a dark room. In E. H. Whinefield (Ed.), Masnavi $i$ ma'navi: Teachings of Rumi (E. H. Whinfield, Trans., p. 185). Ames, IA: Omphaloskepsis. Retrieved from http://rumisite.com/wp-content/uploads/ Masnavi-English.pdf

Sanai, H. (1910). On the blind men and the affair of the elephant. In M. J. Stephenson (Ed.), Enclosed garden of the truth (M. J. Stephenson, Trans., pp. 13-14). Calcutta: Baptist Mission Press. Retrieved from https://archive.org/details/firstbook ofhadiq00sanauoft

Scott, R. (1982). (Producer). Bladerunner. [Motion picture]. United States: Warner Bros.

Sebeok, T. A. (2001). Signs: An introduction to semiotics (2nd ed.). Toronto: University of Toronto Press.

Sousanis, N. (2015). Unflattening. Cambridge, MA: Harvard University Press.

Stiegler, B. (2015). States of shock: Stupidity and knowledge in the twenty-first century. Cambridge, UK: Polity.

Thomsen, H. (2003). Scaffolding target language use. In D. Little, J. Ridley, \& E. Ushioda (Eds.), Learner autonomy in the foreign language classroom: Teacher, learner, 
curriculum and assessment (pp. 29-46). Dublin: Authentik.

van Lier, L. (2004). The ecology and semiotics of language learning: A sociocultural perspective. Boston, MA: Kluwer Academic.

Weiland, P. (Director). (1986). Points of view [Television commercial]. London: Boase Massimi Pollitt. Retrieved from https://www.youtube.com/watch?v=E3hT3KQNxU

Williams, R. (Director). (1965). The Dermis Probe [Animation, short]. United Kingdom: Richard Williams Animation.

\section{APPENDIX}

1 つの視点から見た場面は 1 つの印象がある。印象は観点によって異なる。し かし、すべてを完全に理解するのは、全体を見たときだけである。

Translated from Points of View (1986), directed by Paul Weiland.

\section{Glossary}

CLIL stands for Content and Language Integrated Learning and pertains to teaching subjects such as science and humanities through a foreign language.

Multiliteracies is a term coined in the mid-1990s by the New London Group and is a specific approach to literacy theory and pedagogy.

Multiple literacies theory is a term that builds on multiliteracies but analyses moments of educational breakdown and breakthrough through the prism of Deleuze and Guattari's philosophy of the body, affect and materialism.

'Pataphysics is "the science of imaginary solutions, which symbolically attributes the properties of objects, described by their virtuality, to their lineaments", according to French writer Alfred Jarry (Jarry, Edwards, \& Melville, 2001). We are using 'pataphysics as a playful means to imagine a different set of solutions to the problem of teaching content in the English language education in Japan.

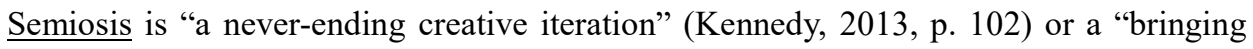
forth a world" (Maturana \& Varela, 2008). 
Applicable level: university, high school

Keywords: multiliteracies, CLIL, Guattari, critical media studies, points of view

Bradley, Joff P.N. (Co-author)

Faculty of Language Studies, Teikyo University, Hachioji campus,

192-0395, Tokyo

E-mail: joff@main.teikyo-u.ac.jp

Cole, David R. (Co-author)

Western Sydney University, Centre for Educational Research Penrith (Kingswood)

J.G.16, Sydney, Australia

E-mail: David.Cole@westernsydney.edu.au

Cabell, Charles (Co-author)

Faculty of Global and Regional Studies Toyo University

5-28-20 Hakusan, Bunkyo-ku, Tokyo 112-8606

E-mail: cabell@toyo.jp

Kennedy, David H. (Co-author)

Faculty of Commerce, Nihon University

Kinuta 5-2-1 Setagaya-ku, Tokyo 157-8570

E-mail: kennedy.harris.david@nihon-u.ac.jp

Poje, Joseph (Co-author)

Faculty of Language Studies, Teikyo University, Hachioji campus,

192-0395, Tokyo

E-mail: 1967fujisan@gmail.com

Received: March 22, 2018

Revised version: May 15, 2018

Accepted: May 26, 2018 